\title{
Avaliação Histológica e Morfométrica de Mamas de Ratas Castradas Submetidas àTerapêutica com Esteróides Sexuais
}

Autor: Luciano de Melo Pompei

Orientadora: Profa. Dra. Filomena Marino Carvalho

Tese de Doutorado apresentada ao Departamento de Obstetrícia e Ginecologia da Faculdade de Medicina da Universidade de São Paulo, em 22 de novembro de 2002.

Objetivo: Estudar as ações do benzoato de estradiol $\left(\mathrm{BE}_{2}\right)$ e do acetato de medroxiprogesterona (AMP) na mama de ratas ooforectomizadas.

Materiais e Métodos: Quarenta ratas ooforectomizadas aos 250 dias de vida, das quais 20 tiveram prole e 20 não, foram aleatoriamente subdivididas para receber um dos seguintes tratamentos por via subcutânea, por 10 semanas: $\mathrm{BE}_{2}$; $\mathrm{AMP} ; \mathrm{BE}_{2}+\mathrm{AMP}$; placebo. Após o tratamento, estudou-se uma mama de cada rata ao microscópio óptico, cuja ocular continha gratículo com 100 pontos. A contagem dos pontos coincidentes com cada estrutura permitiu o cálculo das frações de volume lobular, acinar no lóbulo e na mama, epitelial no lóbulo e na mama, e da luz acinar. Atrofia, secreção e microcalcificações foram avaliadas qualitativamente. Resultados: a) houve equivalência entre AMP e placebo e entre $\mathrm{BE}_{2}$ e $\mathrm{BE}_{2}+\mathrm{AMP}$ para todos os parâmetros ava- liados; b) $\mathrm{BE}_{2}$ e $\mathrm{BE}_{2}+\mathrm{AMP}$ aumentaram as frações lobular, acinar e luminal significativamente em comparação com AMP ou placebo; c) $\mathrm{BE}_{2}$ aumentou a fração epitelial na mama sem significância, enquanto $\mathrm{BE}_{2}+\mathrm{AMP}$ a aumentou com significância comparado ao placebo ou AMP; d) $\mathrm{BE}_{2}$ e $\mathrm{BE}_{2}+\mathrm{AMP}$ incrementaram a atividade secretora; e) houve tendência a maior aumento epitelial no grupo sem prole.

Conclusões: Na mama de rata: a) o AMP só agiu em concomitância com $\mathrm{BE}_{2}$; b) o AMP aumentou a proliferação induzida pelo $\mathrm{BE}_{2}$; c) $\mathrm{BE}_{2}$ e $\mathrm{BE}_{2}+\mathrm{AMP}$ estimularam a diferenciação celular; d) ratas sem prole apresentaram tendência a maior proliferação epitelial.

Palavras-chave: Terapêutica de Reposição Hormonal. Estudo experimental. Epitélio mamário. Proliferação celular. Morfometria. 